the principle is the same with modification in the procedure because the fibroid is larger. The first incision is the satwe, and so is the application of the first pair of clamps and of the speculum in front to keep the bladder out of the way. The morcellation proceeds by the same rules, but is longer and more difficult; nevertheless, the whole fibroid and the uterus and adnexa can be removed in this way without shock or exposure of the intestines. For the morcellation of the myoma, very strong curved scissors aro required, and often it is better to use a long knife curved on the flat; with this the myomatous nodules are soparated from their attachments, and the fibrous structure of the tumor sundered. With strong vulsella forceps the various pieces are brought out and thon they are cut off. Thus the part of the tumor presenting in the vagina is attucked, sundered and removed, while as each portion is taken away another is brought down to the opening, until finally what romains of the tumor is delivered like a child's head, in one mass. 'The whole morcellation goes on within the capsule of the tumor, and the intestines only appear at tho end when the mass is delivered.

I know of no operation requiring more nerve and skill and anatomical knowledge than the morcellation of a myoma of considerable size; bu' when it is over, if properly performed, it is certain that tho patient has less shock and is in a better condition than if the tumor had been removed through the abdominal wall. The specimen which I show, of the size of a cocoanut and removed in thirty pieces, represents the limit as to size which I should care to operate on in this way. The particular advantage of the procedure is the ease and safety with which it enables us to remove small inyomata of the size of the two fists or thereabouts. No tumors should hereafter be allowed to get much larger.

It is interesting to observe how abdominal hysterectomy is performed in France, by the best of operators, for perhaps their preforence of vaginal hysterectomy is partially based on not being acquainted with the latest methods of abdominal hysteroctomy.

I saw Bouilly tie the ovarian arteries, put a rubber ligature around the stump of the uterus, cut the stump off, disinfect with a cautery, rub iodoform into it and drop it; and the woman made a good recovery. He told me the theory was this: He put the rubber ligature round the stump, and dropped it and sewed up the abdominal wound. If the woman was in good condition, it was a matter of a few minutes to open the vagina and take that stump out from below, using clamps. In this case the woman not being in good condition, the rubber ligature was left and the patient recovered.

The second method, that of Richelot, is ingenious. He opens the ablomen and if the fibroid is large, he does not try to make an opening large enough to let it through, but cuts out pieces from the fibroid after delivering the tumor. He peels off the bladder, reflecting the peritoneum down to the vaginal junction which ho opens through into the vagina. 'Thon he intro. duces a long curved clamp into the vagina, and throngh the opening in the anterior fornix, and pushes the posterior blade of the clump through the broud ligament, below the course of the uterine artery; the other blude entering from the front, passes along the auterior face of the broad ligament; when the clamps are closed on oach side, he cuts the tumor out from between them, and then comes some blood from the posterior vaginal arteries. 'To check this he reaches in from above and finds the artery, and then puts on another clamp from below to hold it, taking away the clamp which was put on from above.

Péan has a peculiar method; ho drags out tho tumor through the abdominal incision by piercing it with a huge curved needle with the eyo at the point, on a handle, then he reflects the bladder close down to the cervix, and thrusts the needle through the cervix as low down as possible; then an iron wire is threaded through the eye of the needle and drawn back and cut in two. That lenves the cervix with a loop of wire on each side. The ends of each of these loops he puts into a tourniquet, including the whole broad ligament in the loop; he thus constricts the broad ligaments with a tourniquet on each side and then cuts away the whole tumor including the cervix : next he introduces a clamp on each side, or two if necessary, through the vagina, placing them on the broad ligaments, to control the arteries, and then removes the wire loops.

These seem to be the three principal ways of doing an abdominal hysterectomy in Paris; although the perfected American method of tying the arteries from above has been introduced by one operator very lately, yet it is practically not known, and in consequence the vaginal method is preferred even in cases in which an operator having equal familiarity with our way of doing abiominal hysterectomy would probably prefer it. It is of the greatest importance that the operators of each country should learn the best that those of the other country have to offer, so that finally the indications of the best method in any given case may be established and surgery may thus be perfected.

\section{VAGINAL HYSTERLCTOMY.}

BY (7RO. J. KNGKLMANN, M.D.

1 Have closely observed the status and progress of vaginal hysterectomy, this much-lauded and much-condemned operation, since I first convinced myself of the possibilities of the new procedure, the French method, as it has been called, and of its advantages in its proper sphere.

'The admirable results achieved in 1892 and 1893 , in cases then inoperable by celiotomy, gave just prominence to the vaginal method, which has inaugurated a now era in pelvic surgery; it male successful operation in hitherto doubtful cases possible; it tanght the possibility and the advantages of removal of the of fending uterus, together with the disensed udnexa: and thus not only led to the rapid perfection of the rival abdominal operation, but has opened a large field for major and minor surgical procedures by colpotomy, by this ready and sufe approach to the pelvic viscera.

Vaginal hysterectomy is an established fact. 'loo much may have been claimed for it by enthusiastic

1 prosented bopore tho section for Obstetries and (iymecology of the

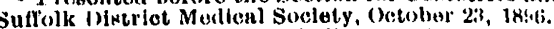

2 Raroly has natomal projudied as a findor in modlent history been more prominent than in tho retarded developunent of this operation, which, great as has hean the fulluence it has exerted on the develop-

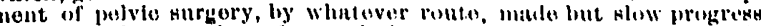
at n Frenrh operation; for such it was pritetieally, mo muter if

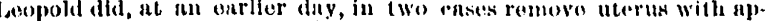

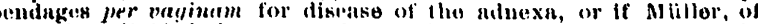
Bern, flret divided the utertus limgitudinally to fincilitute removal:

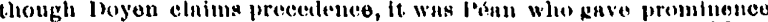
to morcellement which at once opened so wite a fiolit to vaghinal hystoroctomy. 
advocates, hence we should now endeavor to define the sphere and the indications for the operation. It is in this sense that, I shall be glad to say a few words in connection with the interesting and impartial résumé of Dr. Cushing.

'The claim made for vaginal- or colpo-hysterectomy is not that it is to supplant the abdominal operation (celio-hysterectomy), but that it is better adapted to certain conditions, and offers additional resources to the surgeon. If I have expressed myself more forcibly in favor of the vaginal route in my first paper in 1893 . at the New Orleans meeting of the Southern Surgical and Gynecological Association, 8 my assertions were based on conditions then existing ; now the indications for the operation are neither so broad nor so positive, as the progress and success of suprapubic hysterectomy at the hands of Anerican surgeons within these last years must of necessity limit the sphere of the vaginal operation as then represented.

Since Verneuil, in the Paris Surgical Society in 1886, so strenuously opposed vaginal hysterectomy for cancer of the uterus on account of its frightful mortality, great changes have taken place. For malignant disease, which Freund had vainly sought to reach by abrominal section, the operation wus soon accepted; then it was resorted to for disease of the alnexa by Péan and Doyen; by Ségond, of Paris, in 1891, in suppurative conditions for purposes of more perfect drainage; Jacobs, of 13russels, adopted the new method in cases then inoperuble by celiotomy, and with success, while Péan gave broader scope to the work by his method of morcellement.

In Jess than a decade the operation had been developed and perfected until it surpassed in its results the older supravaginal method, for which now again the same low mortality is claimed as for the vaginal route, both being advocated by their adberents for a similar class of cases. In 1894 Jacobs cites 1,540 abdominal sections with a mortality of 5.7 per cent. and 690 vaginal operations with hut 4.49 per cent. mortality. Dr. J. M. Baldy, in 1895.4 cites 224 abilominal hysterectomies by eminent American operators, with a mortality of only 2.7 per cent., as contrasted to the 403 cases of Dr. Jacobs by the vaginal method with 2.9 per cent.

Yot the 224 celiotomies are recent sections by men experienced in the work, while 403 vaginal operations represent the work of one operator, including his first series ; but regardless of quibbles or the playing with figures, it is evident that we have reached a point at which statistics no longer avail; we may be guided by them in the earlier stages of an operation, but now the results attained approach each other too closely, they are almost ideal in both methods, and the relative merits of vaginal and abdominal operation must be determined upon other grounds and upon a more scientific basis than that of statistics only, which are liable to be deceptive.

Let us disregurd the mortality, less than three per cent. by eilier method; and let us disregard also the abdominal cicatrix and the possibility of ven-

"Hysterectomy by Moreollementand the Vagiual Ronto in Polvie Operations in Plice of Luparotomy, 'Transactlons Suutuern Surgical and (iynecological desociation, ix!3.

- Batimoromeuting, Amorican Aynocological Society.

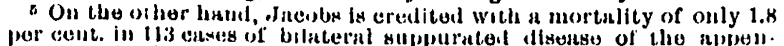

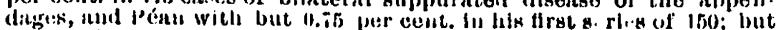

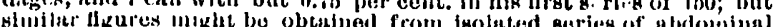
operations as well. tral heruia, both of which have been urged arainst the supravaginal operation. 'The former is purely esthetic and yet has weight with the knowing patients of the present advanced era; the latter is now a much more rare occurrence, with thorough antisepsis and proper suturing of the abdominal walls. I will not throw these objections into the balance against the abdominal operation, although I take them to be somewhat in favor of vaginal hysterectomy.

To arrive at au impartial and practical result, eliminating the question of mortality, of cicatrix and ventral hernia, we must consider -

(1) 'The advautages and disadvantages of the two methods ;

(2) The curative results obtained, the permanent benefit to the patient ;

(3) The class of cases best adapted to each operatiou.

The personal equation is an important factor, and due consideration must be accorded the experience and individuality of the operator, upon which results so largely depend; and in considering the rolative merits of the vaginal and abdominal mechods, we must avoid the mistake usually made of comparing only the forci-pressure, or French method proper, with tho perfected abdominal operation, and remember that for vaginal hysterectomy we may resort to clamp and drainage or to ligature with suture and closure, an ideal aseptic operation.

In favor of the vaginal route is the avoidance of more extensive disturbance of tho peritoneum and the abdominal cavity proper, which is often but littlo involved in the operation, especially in cases of suppurative or inflammatory disease with boarding off of the pelvic cavity; the viscera are not manipulated. The general condition of the patient suffers decidedly less under the vaginal operation, recovery is more rapid and the getting up at an earlier day ; shock, major and minor, is less, although true surgical shock now rarely occurs even after the abdominal operation since the perfection of method and technique.

The vaginal is attacked as unsurgical, and yet the difficulty of technique is cited as against it, which is in itself a contradiction. A skilled hand and intimate acquaintance with the pelvic viscera is an essential to successful operation by this methorl be it by clamp or ligature.

The tield of operation is not as limited as is made to appeur, nor is the operation a blind one, one of touch alone, as has been said ; tho broad, well-adapted retractors of Péan give ample scope for manipulation, and the deep, unilateral vagino-perineal incision of Dührssen opens a field which readily admits of the application of ligature and suture, and can be so enlarged by additional vaginal incision as to overcome all interference of the soft parts, limiting the space as he claims by the pelvic walls only. With good light the eye guides every step, and touch alone need but rarely be depended upon, although we must almit that the tield is a very much larger one and more freely exposed by the abdominal incision with Trendelenburg position and retractors.

Among the advantages of the vaginal operation is the perfect downward drainage secured by the forcipressure method with cautery incision, so essential in suppurative or septic cases. Vaginal hernia, though it may occur, is not as common as the ventral, and the danger from ileus and from injury to the intestines no 
greater than from laparotomy, yet repair of the injured viscera is not as readily accomplished us when exposed in the abdominal incision; the tearing of tissues is not so liable to occur, as the same necessity for the complete separation of all adhesions does not exist as in celiotomy, and firmly agglutinated parts may bo left in situ with perfect safety, cutting away all but the adherent tissue; recovery is not interfered with by reason of the ideal drainage by this methot.

Disadvantages of the vagival method are the inability to deal with suprapelvic complications, and the limitation of our field of observation as well as work by the neighborhood of the pelvic brim; I may also add the greater manual dexterity required of tho surgeon, and yet the sufety and apparent simplicity of the operation which may lead many a novice upon dangerous ground; it is the avoidance of the peritoneal cavity which gives this feeling of security, so that other difficulties are liable to be overlooked.

The post-operative slough and the offensive discharge which is complained of as liable to occur during convalescence is by no means a necessary sequence to the clamp operation, yet may follow where raw tis. sue has been exposed under imperfect asepsis. 'This is avoided by the German method, by the ligature with perfect adaptation of all parts and closure of the vaginal vault. This method also disposes of the objection raised on account of post-operative suffering caused by pressure forcepe and dressing within the vagina; yet even where the clamp is used, this need not occur if instruments are properly disposed of and the dressings properly applied : the clamp is a more rapid method, and must be given preference where rapidity of operation is essential and for friable or edematous liganents in purulent or septic cases where likewise drainage is desirable.

The benefit to the patient, the final curative result, must depend greatly on the skill of the operator, but will be more perfect by the vaginal operation, regardless of the perfection of the abdominal method in cases in which restoration depends upon the disappearance of exudates and infiltration, although drainage for sur. gical recovery only is not essential.

In the selection of cases and in defining the indications for the vaginal operation wo must distinguish between the method by clamp or forci-pressure and that by ligature and suture.

The absolute indication for the clamp operation has been restricted by the perfection of aseptic surgery, which not only enibbles us to dispense to a far greater extent with drainage, but has taught us to avoid it if possible. The indications for the clamp operation are to be found in suppurative pelveo-peritonitis with mul. tiple or non-enucleable foci, in puerperal and other septic conditions with a uterine focus, in cases demanding the operation complicated with exudation and infiltration of tissues and such in which the abdominal cavity proper may be avoided, in which the pelvis is roofed over by the agglutinated viscera: it is indicated when rapidity of operation is essential or shock is to be dreaderl, and I most heartily endorse the plea of Dr. Jacobs for vaginal hysterectomy in the case of laboring women with pelveo-peritonitis with oxudation, who caunot linger under treatment, who must secure speedy restoration to health and resume work.

The vaginal operation by the ligature with closure, and even a thoroughly aseptic clamp operation enables the surgeon to choose the route, ventral or vaginal, in simple suppurative and other uncomplicated conditions or smaller tumors, in accordance with his preference and experience, and the conditions existing in the particular case.

Much is left to individual preference determined by training and the skill of the operator: the greneral surgeon with experience in abdominal operation will select the ventral incision, while the gynecologist familiar with vaginal exploration will prefer this method which must lead che gryweric surgeon to a more thorough and precise knowledge of these parts and their pathology, and will, as I have expressed myself as early as 1893 , inaugurate a new era in pelvic surgery. I then said that the safety and facility with which such operations can bo performed opens up an entirely new field for colpotomy, the breaking up of adhesions, the replacing of the uterns and exploration of the important parts within reach of the finger.

'This and more has been realized : through the vaginal incision, by colpotomy, we sever adhesions and restore the retro-displaced, bound-down uterus with the intrapelvic tampon (Pryor); or by anterior vagino-fixation (Sänger); and the successful treatment of incipient septic peri- and para-nterine disease in its early stages has been made possible by the method of Ilenrotin, who enters through the 1)ouglas, and breaking up adhesions and exudates, if possible before pus forms, drains, thus securing cleansing und absorption with an early recovery by aborting and controlling the nefarious processes; Martin has proven anterior colpotomy, for unilateral disease of tube or ovary and the removal of small cysts and tumors, a safe and simple procedure, as already urged by Jacobs, who penetrated anteriorly or by the Douglins, as indicated, and as it had been resorted to years ago in occasional favorable cases by Battey, by 'Thomas and Baker. Digital exploration of the pelvis, the breaking up of adhesions, and the restoration of relaxed and contracted ligaments will be found safe and satisfactory procedures by anterior or posterior colpotomy, as most accessible.

Whatever may be the extent of its indications, vaginal hysterectomy will always have a field in pelvic surgery by reason of the draimage afforded in one class of cases, and in another by reason of the avoidance of the peritoneal cavity and of the abdominal scar and the assured, or apparent, safety of the interference; whatever the future of the operation, it has already been of inestimable service in leading to more perfect methods in septic and suppurative disease of the pelvis, and to the perfection of the abdominal operation. The new method will remain an important factor in gynecic surgery, and l ask for it a thorough consideration and a serious trial in proper cases, with proper instrumentarium, without which the best efforts may fail.

Buindondes in Soandinavin. - The British Medical Journal summarizes in its issue of December 1 th statistics which havo been collected by Wirluark regardiog blindness in Scandinavia. These show that Denmark had in 1890 for overy 10,000 inhabitants only 5.3 blind, Sweden 8.3, Norway 12.8, Finland 15.5. Compared to other European comtries, Portagal and Russia stand highest, with 20 blind persons for every 10,000 inhubitants, and Holland lowest with only 4.5 . 